\title{
Obtaining Hardened Layers of Heat-Resistant Steels by Plasma-Welding Deposition of Congeneric Materials
}

\author{
Yuri Dmitrievich Shitsyn ${ }^{1} \&$ Dmitry Sergeevich Belinin ${ }^{1}$, Sergey Dmitrievich Neulybin ${ }^{1} \&$ Pavel Sergeevich \\ Kuchev $^{1}$ \\ ${ }^{1}$ Perm National Research Polytechnic University, Russia \\ Correspondence: Yuri Dmitrievich Shitsyn, Perm National Research Polytechnic University, Russia. E-mail: \\ 5ly87@mail.ru
}

$\begin{aligned} & \text { Received: November 27, } 2014 \quad \text { Accepted: December 3, } 2014 \quad \text { Online Published: April 25, } 2015 \\ & \text { doi:10.5539/mas.v9n6p64 }\end{aligned} \quad$ URL: http://dx.doi.org/10.5539/mas.v9n6p64

\begin{abstract}
The paper presents the research results on plasma-hardening of heat-resistant steel layers by plasma-welding deposition of congeneric materials under straight and reverse polarity current. The dependence of the deposited layer quality on the current polarity has been determined. A metallographic examination and measurement of micro-hardness of the deposited layer have been conducted. The dependence of the deposited layer characteristics on the welding parameters has been determined. The obtained results allow the use of plasma-welding deposition to obtain layers with the required strength characteristics using the material, congeneric to the parent material.
\end{abstract}

Keywords: plasma torch, plasma-welding deposition, stainless steel, reverse polarity, micro-hardness, thermal treatment

\section{Introduction}

Welding deposition is one of the most effective methods for applying protective and strengthening coatings that increase the resource of machinery parts and assemblies exposed to intense wear. Welding deposition is used mainly for restoring of worn or damaged parts of machinery and equipment, though in many industries it is already a mandatory flow process that is used in the manufacture of new products. Shells of nuclear reactors and chemical plants, piping valves, top charging equipment of blast furnaces, drilling tools, valves of internal combustion engines, extruder screws and many other parts and products of contemporary engineering cannot be manufactured without welding deposition of stainless steel, wear-resistant, heat-resistant or other steels and alloys with special working properties (Schechter, Reznitsky, 1982).

Manufacturing welding deposition of rapidly wearing or most heavily loaded parts can increase their service life, save the industry from having to make a large number of spare parts, improve efficiency and reliability of the machines, and reduce the cost of their operation. For this reason, increased use of manufacturing welding deposits ensures progress in various branches of engineering (Hasuy A., Morigaki O., 1985).

A promising way of improving the surface treatment technology is the development and implementation of processes using highly concentrated energy sources, including plasma technologies (Puzryakov, 1997). Plasma arc provides a powerful thermal effect on the treatment zone. Possibility of controlling the energy concentration allows changing both the processing width and the depth within a wide range.

Plasma-welding deposition or surfacing is a deposition of metal layer on the surface of the workpiece using the compressed arc. Moreover, heating the welded surface by plasma arc provides surface heat treatment, thereby improving the performance characteristics of the working layer.

One of the important parameters of the welding deposition process is the depth of weld penetration into the parent metal: the lower the depth of weld penetration, the smaller the share of the parent metal in the welded layer (Safonov, 2001).

When carrying out plasma welding deposition one strives to provide the minimum penetration of the parent metal into the weld. When conducting welding deposition by direct arc, minimal penetration of the parent metal is provided only at relatively low currents (Balanovsky, 2000). Plasma welding deposition at straight polarity is associated with certain drawbacks: higher degree of contamination of the deposition metal by oxides, formed 
during welding. However, most of the known methods of plasma welding deposition are performed at straight polarity.

The welding penetration depth includes a transition zone from the parent metal to weld. For some materials, this zone is considered the most dangerous in terms of metal fracture. Metal in transition zone is embrittled due to high cooling rate of the metal in weld; it has an increased tendency to form cold cracking due to the large heterogeneity of chemical composition of metal and thus a large difference in the coefficients of linear expansion (Ford, 1987). It follows thence that the greater the depth of weld penetration, the greater the area of the weakened zone and the lower the strength of the workpiece. Conversely, the smaller the depth of weld penetration, the least is lost of workpiece strength. The depth of weld penetration of the parent metal and the properties of the transition zone are influenced by rate of energy input and the cooling rate, consequently (Jackson, 1969).

The following welding deposition technologies are the most common:

- welding deposition by plasma jet with a conductive filler metal wire;

- welding deposition by plasma arc with a neutral and conductive filler metal wire;

- welding deposition by plasma arc with hot wires;

- welding deposition by plasma arc with melting electrode; and

- plasma-powder welding deposition.

Plasma-powder technique is the most common technology of plasma-welding deposition. It can significantly broaden the range of alloys deposited by a mechanized way, since the filler powders, necessary for this process, can be produced virtually from any filler alloy regardless of the degree of doping, hardness, ductility and other properties. Due to the low penetration of the parent metal, good formation, the optimum thickness and high quality of the deposited layer plasma-powder technology, compared to other welding deposition techniques, provides a more economical use of welded materials, reduces the cost of subsequent mechanical processing of deposited work pieces and increases their durability. The process of plasma-powder deposition can be easily automated (Vainerman, 1969).

\section{Technique}

The aim of this work is to study plasma-welding deposition of the 40X13 grade steel at the straight and reverse polarity.

Steel of the 40X13 grade is heat- and corrosion-resistant highly alloyed steel of the martensitic grade. The most common alloying element in heat-resistant steels and alloys is chromium $(\mathrm{Cr})$. Favorable effect exerted by chromium on the heat resistance and high-temperature strength is the main reason for which chromium was introduced in all steels, designed for long-term use at high temperatures in continuous contact of the metal surface with oxygen and nitrogen from the air, the coal combustion products, natural gas, or heavy oil of varying degree of contamination by aggressive additives of vanadium, sulfur and other components. In corrosion-resistant steels chrome plays a dual role. When its content is more than $12 \%$, electrochemical potential of steel increases sharply, steel "ennobles" and becomes more stable in the electrolyte solutions. At the same time, the chromium contributes to the formation on the metal surface of an oxide film, dense and strong enough to protect the metal against the corrosive environment. This resistant chromium film protects steel against oxidation at high temperatures, i.e. increases its heat resistance. Thus, high-chromium steels are resistant to chemical and electrochemical corrosion in oxidizing environments (Oiler, 1983).

Along with the high corrosion resistance, steels containing $12-14 \%$ of $\mathrm{Cr}$, have high resistance and heat resistance (significantly higher than that for the low and medium alloy chromium and chromium-molybdenum steels).

Due to the mentioned combination of the properties, high-chromium steels are widely used in various fields of national economy. With high mechanical and anticorrosion properties, high-chromium steels have lower technological properties, including reduced weld ability, a tendency to temper brittleness, formation of segregations and cold cracks. This is due to the features of phase diagram of high-chromium steels, as well as features of structural and phase transformations occurring during heating and cooling.

Chrome refers to the alloying elements, stabilizing $\alpha$-phase in iron alloys and reducing the area of existence of $\gamma$-phase. Introducing into iron-chromium alloys of other ferrite-stabilizing elements (Mo, W, V, Ti, Si, etc.) still more narrows the $\gamma$-region, while at the same time the austenite-stabilizing elements $(\mathrm{C}, \mathrm{Mn}, \mathrm{Ni}, \mathrm{Cu})$ expand this region. Carbon, moreover, leads to the formation of chromium carbides, depleting solid solution by chromium. 
Martensitic high-chromium steels comprise a core group of high-chromium steels. They contain $8-14 \%$ of chromium and $0.06-0.4 \%$ of carbon, and some other alloying elements to impart special properties. The presence of carbon in steels at high chromium content allows obtaining the combination of corrosion resistance and hardening of different degree at the martensitic transformation.

Martensitic grade steels are characterized by a combination of properties that meet the extremely wide range of requirements.

Chrome steels undergoing $\gamma$ - $\alpha$-transformation, i.e. being in a concentration range corresponding to existence of $\gamma$-phase, are attributed to martensite steels due to very small critical cooling rate of steels containing more than 5\% of $\mathrm{Cr}$, even at a small carbon content.

Due to the presence of the polymorphic transformation, these steels can be treated thermally. The higher the carbon content in the steel, the higher strength can be obtained after both the quenching and air-hardening. Only steel with carbon content less than $0.05 \%$ practically cannot be quenched and is a ferrite steel. The steel hardness after heating above the $\mathrm{Ac}_{3}$ (up to $\gamma$-state) and cooling in both oil and air is identical; this indicates that when cooled in a wide range of rates the steel structure is mainly martensitic, though at a slower cooling rates the steel can preserve a certain amount of ferrite.

Increasing the carbon content in steels with $13 \%$ of $\mathrm{Cr}$ lowers the corrosion resistance. With increasing carbon content greater than $0.3 \%$ the corrosion rate increases most noticeably. This is explained by the fact that during the annealing in case of presence of carbon in the steel, chromium carbides are formed, mainly $\mathrm{Cr}_{23} \mathrm{C}_{6}$. At that, solid solution is substantially depleted of chromium that reduces the electro-chemical potential and its corrosion resistance. Thus, the formation of carbides in high-chromium steels adversely affects the corrosion resistance.

Chrome steels of concerned grade apart from the high corrosion resistance have other important properties, namely enhanced heat resistance and temperature strength. Increased heat resistance of high-chromium steels, even without additional doping, is associated with a high content of chromium in solid solution; $\mathrm{Cr} / \mathrm{C}$ ratio in these steels is much higher than the critical value. Furthermore, in case of sufficient carbon content in these steels, they are quenched to martensite even under cooling in air. Characteristically, the martensitic decay in these steels occurs at a fairly low temperature $\left(150-250^{\circ} \mathrm{C}\right)$ that leads to significant distortion and tension of the structures with high dislocations concentration. In addition, the presence in such steel of a chromium carbide, which is stable and relatively difficultly coagulable ( $\mathrm{of}_{23} \mathrm{C}_{6}$ type) at a content in the steel of $12 \%$ of $\mathrm{Cr}$ or more, will result in additional hardening of the martensite due to blocking of existing dislocations by carbide particles (Maslenkov, 1983).

Such hardening provided to be stable at a high temperature as well, due to stability at heating of high-chromium martensite, as well as enhanced stability against coagulation of carbide phase (Sosnin et al., 2002).

An additional increase in the temperature strength of high-chromium martensitic steels is achieved by introducing carbide forming elements (W, Mo, V, Ni). These elements increase the dispersion of the carbide phase and its stability against coagulation, increasing thereby the effect of strengthening and retaining strength when heated. Furthermore, the presence of these elements in the steel leads to formation of a special intermetallic phase $\mathrm{Fe}_{3}(\mathrm{~W}, \mathrm{Mo})$ in finely dispersed form. Its nodules occur on crystal defects in the martensite that gives additional stable hardening when heated.

Along with the positive influence of Mo, $\mathrm{V}$ and $\mathrm{W}$ on the heat resistance, one should take into account that these elements stabilize $\alpha$-phase, promoting narrowing of $\gamma$-area. Therefore, they can contribute to increase the amount of ferrite in the steel, making it not fully martensitic, but martensitic-ferrite. The appearance in such steels of ferrite in concentration more than $20 \%$ contributes to a reduction in strength and heat resistance. To increase the stability of $\gamma$-phase, expanding $\gamma$-area and reducing the amount of ferrite, sometimes a small amount of nickel is added into the high-hardness steel. This allows simultaneous reduction of the critical cooling rate and lowering of martensitic decomposition temperature that result in some increase of strength. However, doping by Mo, V and $\mathrm{W}$ increases the cost of the steel.

The mechanical properties of high-chromium martensitic steels and their welds are determined by their actual chemical composition and thermal treatment regimes, which can be used to control both the properties of the martensitic matrix and the final phase composition, as well as the structure of steels. Significant impact on the mechanical properties of steel have the quantity, size and geometric shape of $\delta$-ferrite, which generally contributes to reduction in ductility and impact hardness without substantial affecting the tensile strength and yield strength.

Increased tendency of martensitic steels to brittle fracture in the state of quenching complicates their processing 
technology. At the carbon content more than $0.1 \%$ martensitic steels are prone to form cold cracking due to a high degree of the martensite lattice tetragonality (Leschinsky, 1987).

Cold cracks are one type of local destruction of compounds. Three factors are determinative in the formation of cold cracks: the hardening structures, increased stress of the first kind and the saturation of the metal with hydrogen. Propensity of steels towards formation of cold cracks is related to their hardenability, i.e. increasing hardness under the influence of the thermal hardening cycle and saturation of metal by hydrogen. Since hardenability of steels increases with increasing doping level, the tendency to form cold cracks is roughly estimated by carbon equivalent indicator $\mathrm{C}_{\mathrm{eq}}(1.1)$.

$$
C_{e q}=C+\frac{M n}{6}+\frac{C r}{5}+\frac{M o}{5}+\frac{V}{5}+\frac{N i+C u}{15}
$$

By reducing the carbon content the viscosity of the martensite increases, though formed structurally free $\delta$-ferrite, in turn, gives it a high brittleness. Therefore, cracks may occur during continuous cooling at temperatures below $\mathrm{T}_{\mathrm{m} . \mathrm{n} .}$, as well as during holding the steel at normal temperature (delayed fracture).

For high-chromium steels the temperature corresponding to origin of martensite transformation does not exceed $360^{\circ} \mathrm{C}$, while the end temperature is $240^{\circ} \mathrm{C}$. With the increase of carbon content $\mathrm{T}_{\mathrm{m} . n .}$ and $\mathrm{T}_{\mathrm{m} . \mathrm{k} \text {. }}$ drop even more that leads to an increase in hardness and brittleness of the martensite. Martensitic transformation in these steels has two features that adversely affect the formation of cold cracks. Upon cooling the steel from heating temperatures of the austenitic state (full or partial) martensite decomposition occurs in a wide range of cooling rates that causes the obligatory formation in the treated area of a fully martensitic structure, sometimes with some amount of austenite (increased carbon content, alloying by nickel) or ferrite (low carbon content, alloying by ferrite-promoting elements). Another feature of the martensitic transformation that provides increased tendency of steel to form cold cracks is that the martensitic decomposition occurs at lower temperature (about $150^{\circ} \mathrm{C}$ ), eliminating the self-tempering processes. The martensite, formed under these conditions, has increased level of micro-strains and dislocations concentration, which become blocked. This leads to excessive fragile (Fetisov et al., 2005).

One more feature of the steels of martensitic grade complicates the surface treatment process conditions. Due to the fact that the martensitic steels, including heat-resistant high-chromium steels, can be thermally improved and are used after quenching and high-temperature tempering, the sections of heat-affected zones (HAZ), which were heated during processing to a temperature close to $A_{C l}$, soften (Short et al., 1995). To avoid such softening it is necessary to carry out complex thermal treatment, namely air hardening and tempering. The best combination of properties of the $40 \mathrm{X} 13$ grade steel is provided when quenched at $1000-1050^{\circ} \mathrm{C}$ in oil or air with subsequent tempering at $200-600^{\circ} \mathrm{C}$. This ensures obtaining the hardness of the order of $55 \mathrm{HRC}$.

Selection of welding deposition mode depends on the thickness of the deposited layer. The choice of deposited materials is based on the requirements applicable to the metal of friction surfaces, depending on the type of wear (Leskov, 1981). For example, abrasive wear conditions require high hardness of welding deposited metal, which is provided by the use of deposited materials with a higher-than-average content of carbon, chromium, manganese, and tungsten. For the corrosion wear resistance conditions, the firmness is achieved by doping the metal with chromium in an amount greater than $12 \%$ (stainless steels).

Not only wires and metal powders, but nonmetal powder (ceramic powder), can be used as the filler material. This allows application of ceramics to metals that makes it possible to achieve the required quality of product and solve actual problems of improving the durability of machines parts and units (Tsvetkov, 1980).

For this purpose we choose most simple scheme for plasma arc welding deposition by the direct arc with supply of de-energized filler wire (Figure 1). 


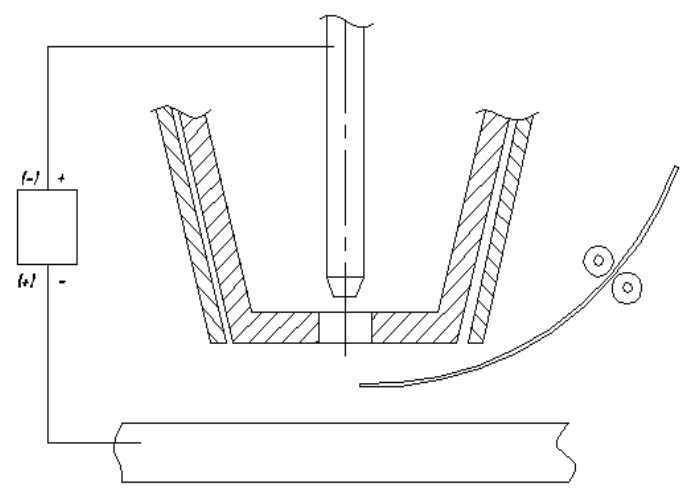

Figure 1. Scheme of welding deposition by the direct arc

Meanwhile, reverse polarity plasma-welding deposition has several advantages: first, a cathode cleaning, which provides good surface wettability and spreading of the deposited metal; second, a dispersal of heat input into the treated workpiece that reduces the welding penetration depth and increases the width of the weld bead; and the third, a lack of internal defects in the deposited layer.

Finally, there are a number of metals, which principally cannot be used for quality straight polarity welding deposition. This is primarily non-ferrous metals and their alloys.

The limited scope of the application of the reverse polarity welding deposition is due to the lack of reliable plasma torches, offered by the industry and applicable for the reverse polarity, as well as due to the common opinion about the lower efficiency of the reverse polarity welding deposition process (Rykalin, 1985).

Deposition rate, the width of the deposited layer per pass, the height of the weld, the depth of the weld penetration into the parent metal, the efficiency of the process, and the defectiveness of the deposited layer depend on many factors, including the polarity (Livshits, Hakimov, 1989).

When contacting the purified surfaces with the atmosphere, they are subjected to rapid re-formation of the oxide film due to its high affinity for oxygen. Therefore, it is preferable to carry out removal of the oxide directly during the welding (welding deposition), while the treatment zone should be protected against repeated oxidation until compound is formed. Such an opportunity is available using the reverse polarity plasma processing of metals. The workpiece is subjected to compressed arc of reverse polarity (in this case the workpiece is the cathode), the treatment zone is protected by argon, injected through the protective nozzle of the plasma torch (Smirnov et al., 2001).

Due to the cathode cleaning phenomenon, the oxide films and other contaminants are removed from the surface. Cathode cleaning provides a good surface wetting and spreading of the welded metal.

The great advantage of the reverse polarity welding deposition is also the dispersal of heat input into the workpiece that makes it possible to reduce the depth of welding penetration and increase the width of the weld bead (Khurtsidze et al., 1978).

Technological parameters of plasma-welding deposition mode are as follows: the magnitude and polarity of the deposition current $\left(I_{d}\right)$, plasma-supporting gas and protective gas flow rates $\left(Q_{s}\right.$ and $\left.Q_{p}\right)$, plasma torch conveying speed relative to the workpiece $\left(V_{c}\right)$, or vice versa, and the feed rate of the filler wire $\left(V_{w}\right)$.

The following modes were used for conducting the research on reverse polarity plasma-welding deposition:

Table 1. Plasma-surfacing conditions

\begin{tabular}{ccccc}
\hline Sample's No & $I_{d}, \mathrm{~A}$ & $V_{w}, \mathrm{~m} / \mathrm{h}$ & $Q_{s}, 1 / \mathrm{min}$ & $Q_{p}, 1 / \mathrm{min}$ \\
\hline 1 & 180 & 8.4 & 3.8 & 5.5 \\
\hline
\end{tabular}

The work piece was a roller of over $200 \mathrm{~kg}$ in weight and the diameter of $240 \mathrm{~mm}$, made of $40 \mathrm{X} 13$ grade steel (Figure 2).

The surface preparation quality for welding deposition was quite poor. At the same time the requirements to 
surface quality after welding deposition were rather high in terms of cleanliness and accuracy.

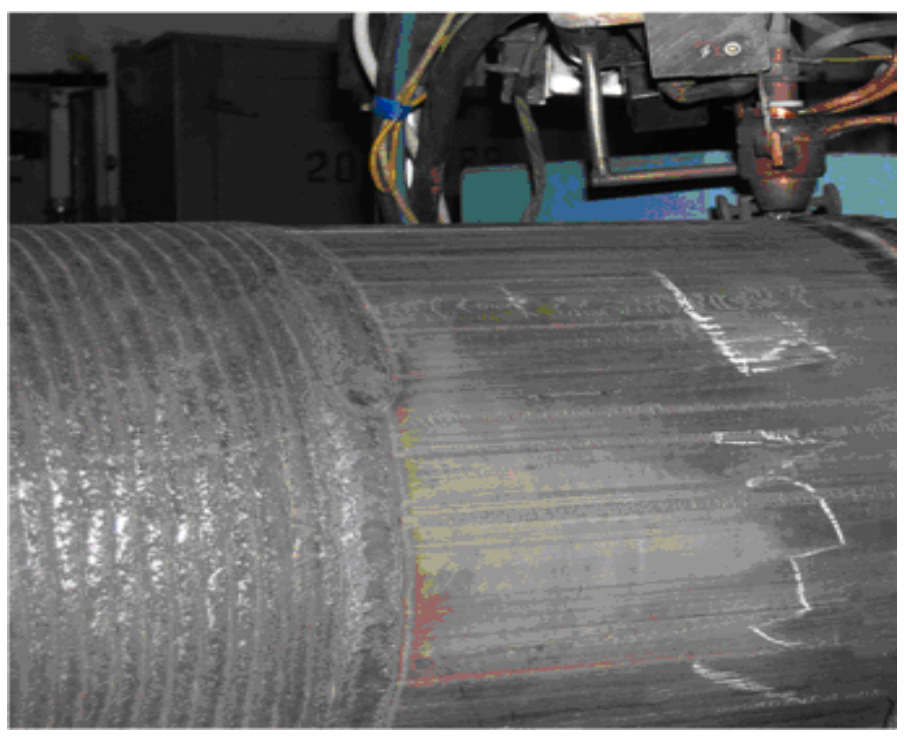

Figure 2. Appearance of the work piece with 40X13 steel layer welded at a current of reverse polarity

Also, due to the cathode cleaning effect, the time and the cost of preparing the workpiece surface for welding reduce, increasing thereby the deposition productivity (Schitsyn, Tytkin, 1995).

\section{Results}

Conducted metallographic study yielded the following results (Figure 2):

According to the analysis of the metal welding macrostructure, authors determined that the welding width per pass was $24.5 \mathrm{~mm}$, welding height was $3.7 \mathrm{~mm}$, welding penetration depth into the parent metal was $0.4 \ldots 0.5$ $\mathrm{mm}$.

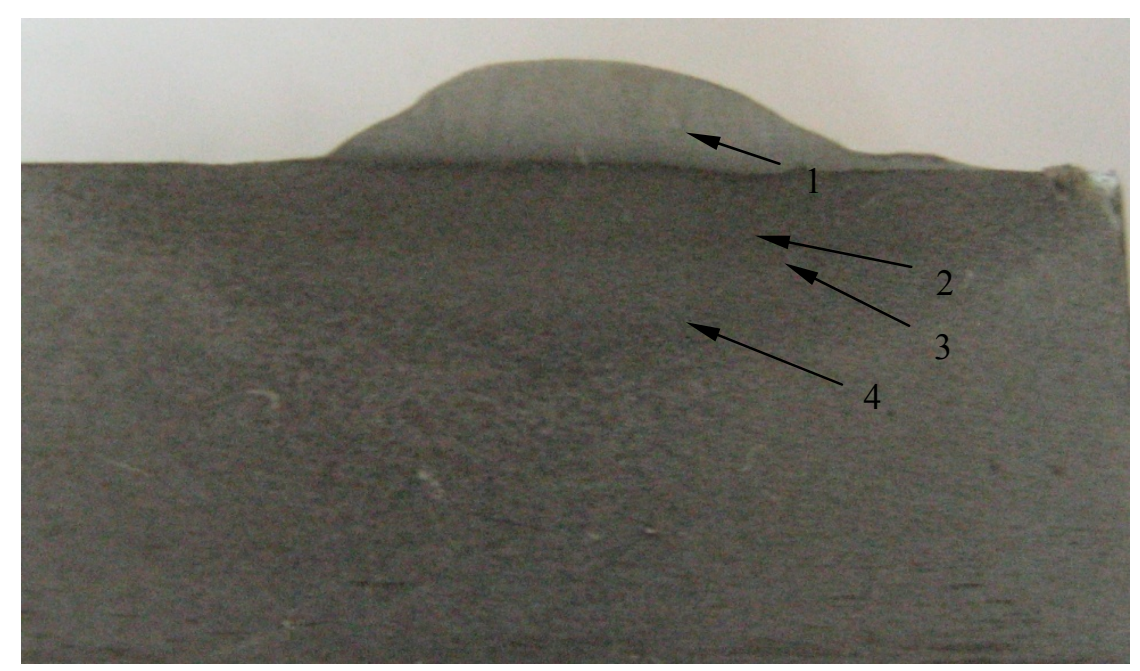

Figure 3. Macrosection (x8) of deposited bead at a reverse polarity current

The following was determined during the microstructure analysis of the main areas of welding deposits:

The welded metal has a structure of the cast material of the cellular-dendritic texture, which is typical of welds. At the weld line dendritic crystals have branches of the first order, oriented towards the heat removal. With distance from the weld line the branches of the second order appear. The deposited metal has a dendritic structure of the martensitic type (Figure 4). The structure of the section $\# 2$ : welding lines represent a structure of tempered martensite with the austenite grain boundaries. The width of the weld line is $0.25 \ldots 0.55 \mathrm{~mm}$ (Figure $5)$. 


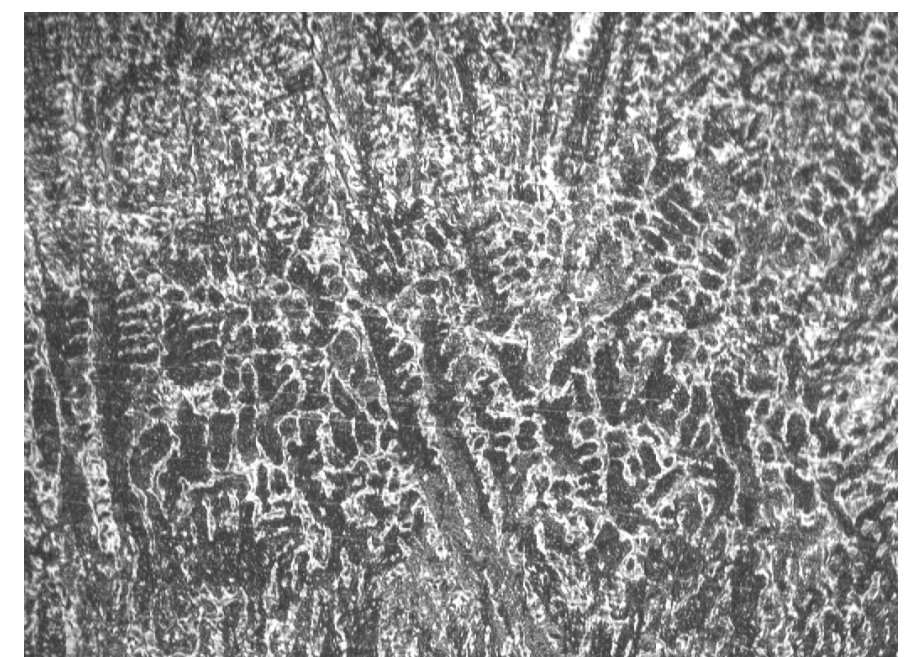

Figure 4. Structure of deposited metal. Section \#1 (x400)

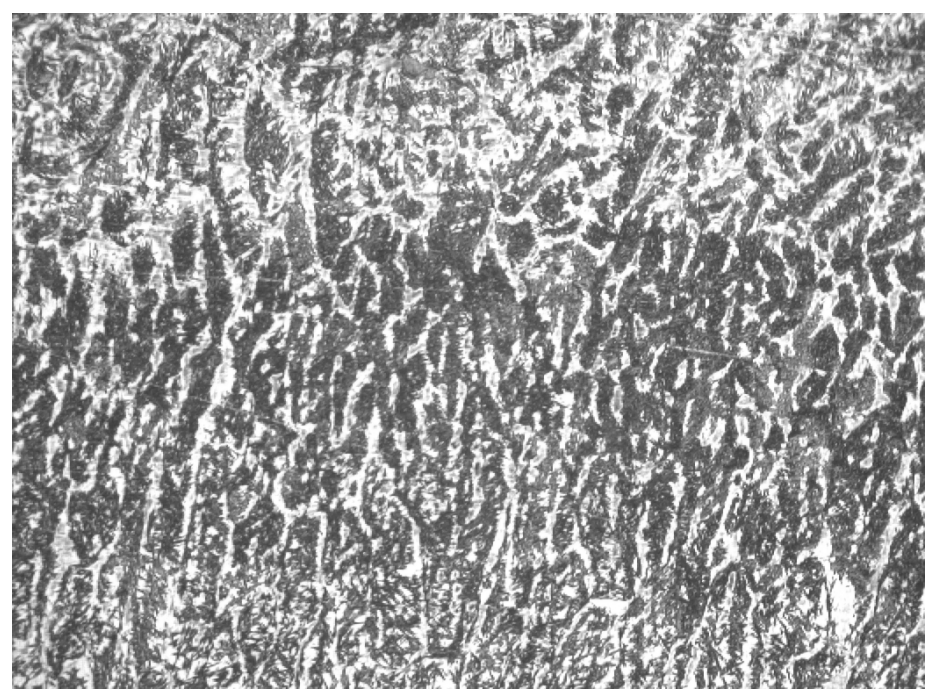

Figure 5. Structure of the welding line. Section \#2 (x400)

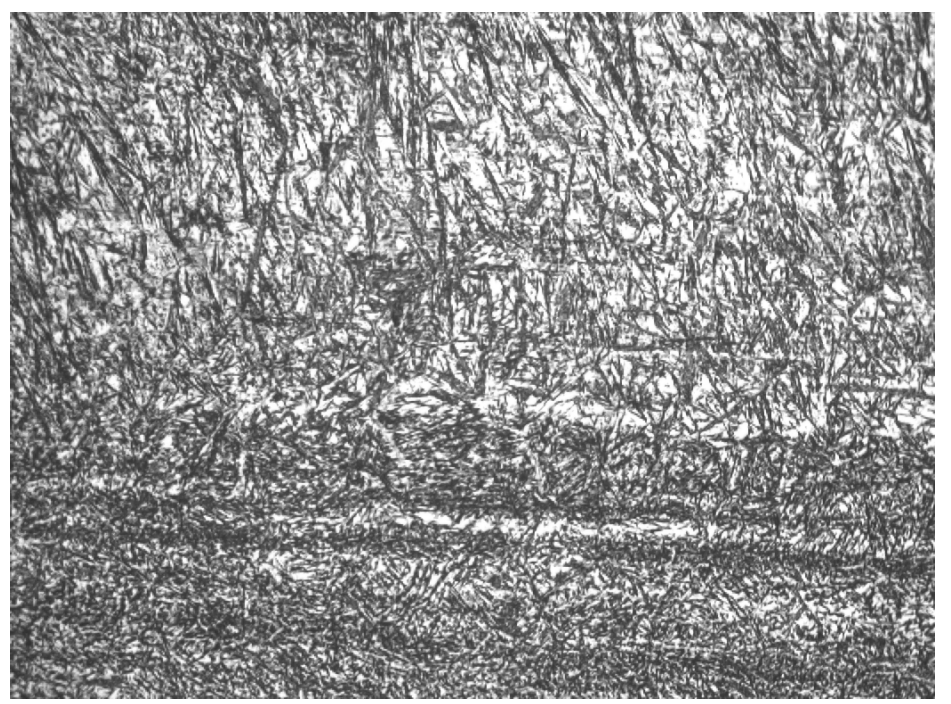

Figure 6. Structure of the heat-affected zone behind the weld line. Section \#3 (x400)

The structure of the initial section of the heat-affected zone, located directly behind the weld line, is the 
martensite with the austenite grains nodules. The depth of this zone is approximately $0.86 \ldots 1$-. 2 mm (Figure 6).

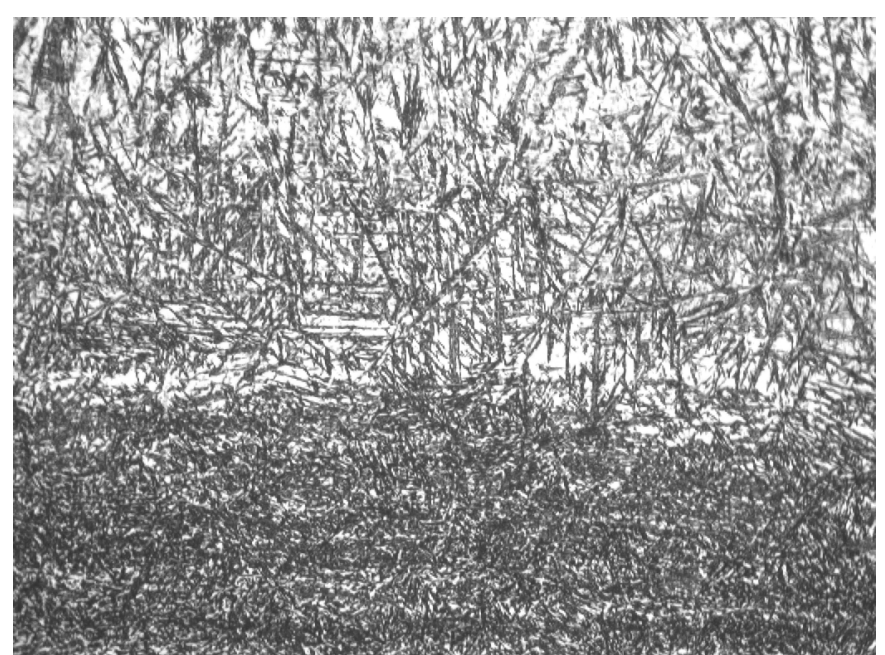

Figure 7. Structure of the heat-affected zone. Section \#4 (x400)

Structure of the section \#4, i.e. heat-affected zone, is granular perlite with additional decay (Figure 7).

The structure of the parent material is a tempered sorbite (Figure 8).

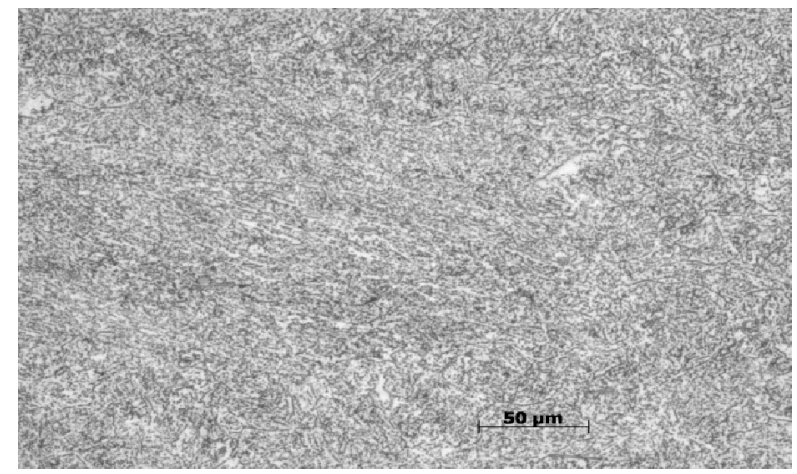

Figure 8. Structure of the parent material (x400)

The results of the zonal micro-hardness measurements are shown in the Table below:

Table 2. The results of the zonal micro-hardness measurements of the sample \#1

\begin{tabular}{|c|c|c|c|c|}
\hline \multirow[b]{2}{*}{ Sample's \# } & \multicolumn{4}{|c|}{ Zonal micro-hardness, $\mathrm{H}_{\mu 50}, \mathrm{kgf} / \mathrm{mm}^{2}$} \\
\hline & $\begin{array}{l}\text { Welding deposited } \\
\text { material (1) }\end{array}$ & Weld line (2) & $\begin{array}{l}\text { Heat-affected zone } \\
(3,4)\end{array}$ & Parent material \\
\hline 1 & $544 \ldots 586$ & $492 \ldots 542$ & $460 \ldots 542$ & $207 \ldots 215$ \\
\hline
\end{tabular}

The weld bead, obtained during the straight polarity welding deposition will have a smaller width than the weld bead deposited at the reverse polarity. When depositing at the reverse polarity, energy is concentrated on the metal surface. In other words, the proportion of involving the parent metal in the deposited metal during the straight polarity welding is significantly higher than that corresponding to reverse polarity. Meanwhile, today in the Russian Federation, about $80 \%$ of plasma-welding deposition processes are conducted at straight polarity. This is due to the load on the plasma torch, which at plasma-welding deposition at the straight polarity is 
significantly less than that at the reverse polarity.

To conduct comparative studies of the straight polarity welding deposition, authors used the workpiece, shown in Figure 9, and applied the modes similar to the reverse polarity welding deposition (Table 1).

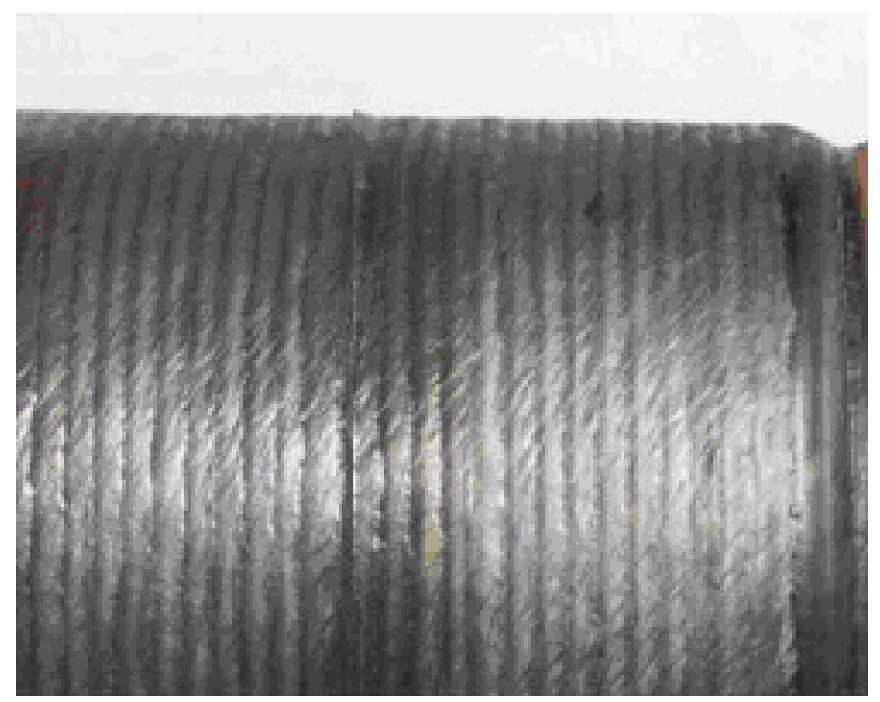

Figure 9. Appearance of the workpiece with 40X13 steel layer welded at a current of straight polarity

Metallographic study, conducted using similar equipment, allowed authors to reveal the following (Figure 10):

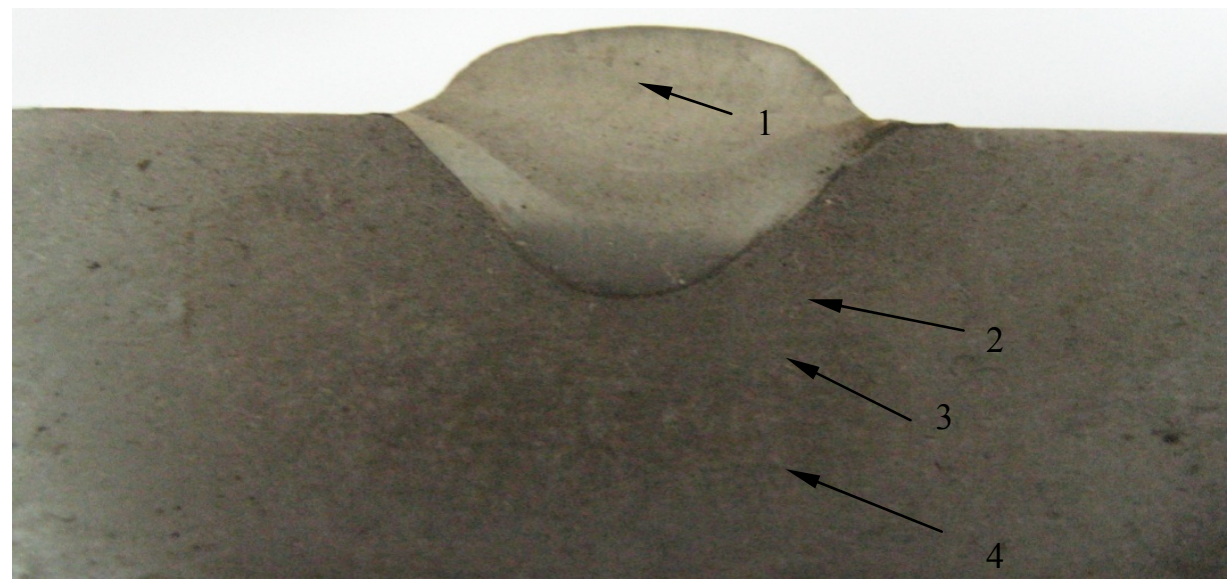

Figure 10. Macrosection (x8) of deposited bead at a straight polarity current

Welding width per one pass was $12.5 \mathrm{~mm}$, welding height was $3.2 \mathrm{~mm}$, welding penetration depth into the parent metal was $1.7 \mathrm{~mm}$. In contrast to the reverse polarity welding deposition, the weld bead has a smaller width, though slightly greater height. At that, the welding penetration depth into the parent metal is noticeably greater.

Similarly to the sample, deposited at the reverse polarity, the deposited metal has a dendritic structure of the martensitic type with the distinguished delta-ferrite (Figure 11). 


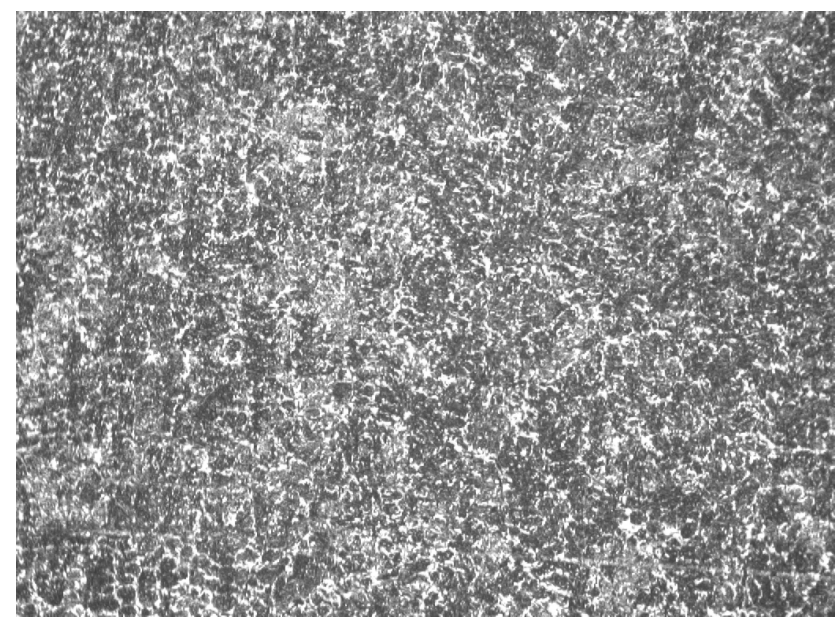

Figure 11. Microstructure (x400) of the weld bead at the straight polarity current. Section \#1

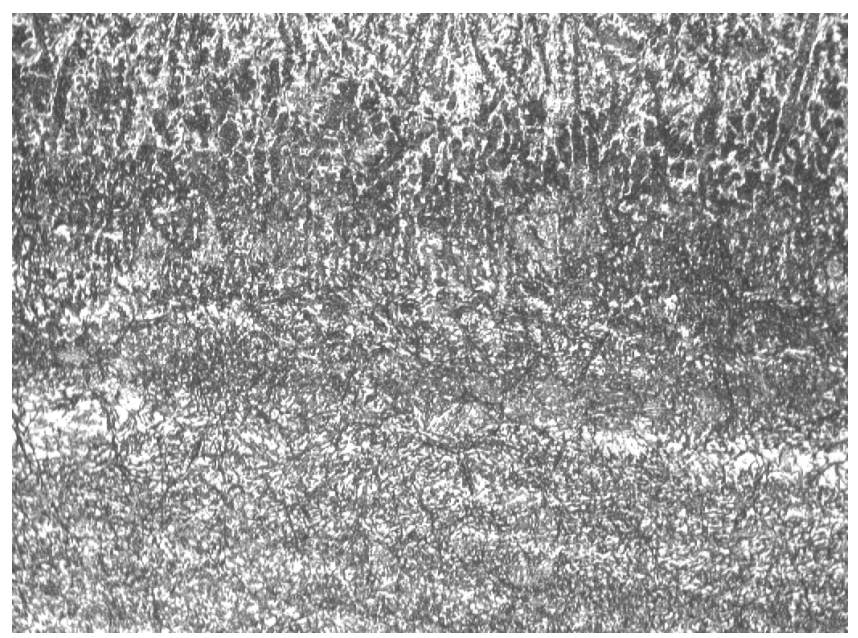

Figure 12. Microstructure (x400) of the weld line. Section \#2

Structure of the section \#2: weld line is a structure of tempered martensite with the boundaries of large austenite grains (Figure 12).

The structure of the initial section of the heat-affected zone, located directly behind the weld line, is the martensite with the nodules of the austenite grains. The depth of this zone is approximately $1.06 \ldots 1-25 \mathrm{~mm}$ (Figure13). The structure of the heat affected zone (Figure 14) is a perlite. The depth of the heat-affected zone is about $2.85 \mathrm{~mm}$.

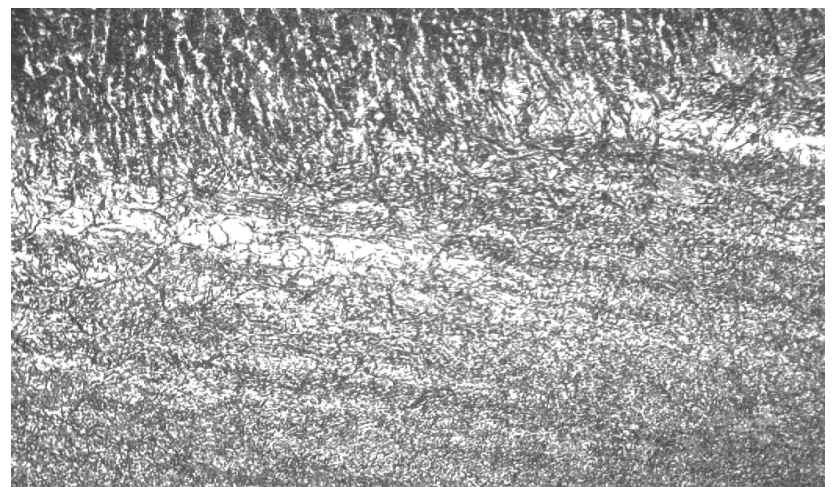

Figure 13. Microstructure $(x 400)$ of the initial section of the heat-affected zone directly behind the weld line. Section \#3 


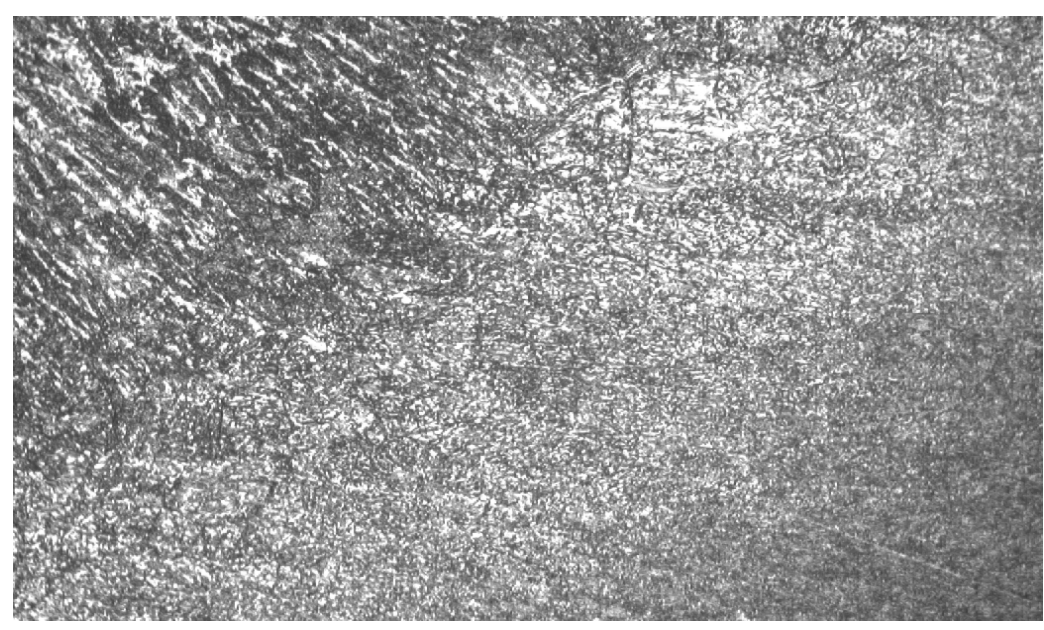

Figure 14. Microstructure (x400) of the heat-affected zone. Section \#4

The results of the zonal micro-hardness measurements are shown in Table 3:

Table 3. The results of the zonal micro-hardness measurements in the sample \#2

\begin{tabular}{|c|c|c|c|c|}
\hline \multirow[b]{2}{*}{ Sample's \# } & \multicolumn{4}{|c|}{ Zonal micro-hardness, $\mathrm{H}_{\mathrm{u} 50}, \mathrm{kgf} / \mathrm{mm}^{2}$} \\
\hline & $\begin{array}{l}\text { Welding deposited } \\
\text { material (1) }\end{array}$ & Weld line (2) & $\begin{array}{c}\text { Heat-affected zone } \\
(3,4)\end{array}$ & Parent material \\
\hline 2 & $525 \ldots 564$ & $547 \ldots 570$ & $432 \ldots 538$ & $207 \ldots 215$ \\
\hline
\end{tabular}

\section{Discussion}

Thus, obtaining the hardened layer with the desired characteristics is possible also through welding deposition; at that, as is obvious from the study, geometric characteristics of the hardened layer can be controlled within sufficiently wide limits. Besides deposited material with high hardness, the structure and properties of the parent material are changed as well due to plasma heating. Depending on the polarity, the depth of welding penetration into the parent metal varies from a few tenths of millimeter (when applying a current of reversed polarity) to several millimeters (when applying a current of straight polarity). However, increase of the depth of weld penetration into the parent metal leads to overheating of the entire workpiece and thus to appearance of the defects, both geometric and structural. Application of the straight polarity plasma-welding deposition makes it possible to increase the total thickness of the hardened layer, though there is a risk of overheating the workpiece and the appearance of strains and defects. Reverse polarity plasma-welding deposition allows reducing the share of the parent metal and increase the width of the deposited layer per pass. The larger width of deposition per pass makes it possible to increase the process productivity and reduce the risk of overheating the workpiece without loss in quality of the hardened layer.

\section{Conclusion}

1. It is shown that the required characteristics of the working layer can be achieved by plasma-welding deposition of the material congeneric to the parent material.

2. The deposited metal layer thickness is a few millimeters that together with the surface hardening zone of the parent metal allows obtaining sufficiently large layers in terms of their total depth (from 3 to $5.5 \mathrm{~mm}$ ) having high hardness (52-60 HRC).

3. When conducting the straight polarity plasma-welding deposition, the deposited bead width is 12 to $15 \mathrm{~mm}$, and the penetration depth into the parent metal is $1.2-1.7 \mathrm{~mm}$.

4. Application of the reverse polarity plasma-welding deposition allows increasing the width of the deposited bead from 19 to $23 \mathrm{~mm}$ per pass at the similar regime parameters, as well as reducing the penetration depth of the parent metal into the weld (from 0.25 to $0.6 \mathrm{~mm}$ ).

5. The large width of weld bead per pass makes it possible to increase the process productivity and reduce the risk of workpiece overheating without loss in the quality of the hardened layer. 
6. Minimum deformation of the workpiece shows that suggested technology allows one to improve the accuracy when manufacturing the workpiece, as well as to reduce the complexity of machining and manufacturing costs.

\section{Acknowledgements}

The work is performed in the framework of the project under the state assignment \# 11.1196.2014/K under the support of the Ministry of Education and Science of the Russian Federation.

\section{References}

Balanovsky, A. (2000). Development of plasma technologies: Welding, welding deposition, hardening, cutting. Welding in Siberia, 2, 8-19.

Fetisov, G., Krpman, M., \& Matiunin, V. (2005). Materials science and technology of metals. M.; Higher School.

Hasui, A., \& Morigaki, O. (1985). Welding deposition and spraying. M.: Mechanical Engineering.

Khurtsidze, G., Dudko, D., \& Kirnienko A. (1978).Thermal efficiency of arc compressed by radial gas flow. Automatic Welding, 8, 67-68.

Korotkov, V., Troshin, O., \& Berdnikov, A. (1995). Plasma quenching by scanned arc without melting the surface. Physics and Chemistry of Materials Processing, 2, 101-106.

Leschshinsky, L., Samotugin, S., \& Pirch, I. (1987). Effect of surface hardening technology by highly concentrated heating source on the structure and fracture toughness of weld material and carbon steels. Welding Industry, 5, 3-6.

Leskov, G. (1981). Heating sources at welding. Welding in the USSR. M.: Nauka.

Livshits, L., \& Hakimov, A. (1989). Physical metallurgy of welding and heat treatment of welded joints. M.: Mechanical Engineering.

Maslenkov, S. (1983). Heat-resistant steels and alloys. Reference book. M.: Metallurgy.

Puzryakov, A. (1997). New developments and prospects for the use of plasma technologies. Welding Production, 2, 21-25.

Rykalin, N., Uglov, A., \& Anischenko, L. (1985). High-temperature process technologies: Thermal physical foundations. M.: Nauka.

Safonov, E. (2001). Evaluating the effectiveness of renovations technology. Proceedings of the 6th all-Russian seminar on engineering and physical problems of new technologies, Moscow.

Schechter, S., \& Reznitsky, A. (1982). Welding deposition of metals. M.: Mechanical Engineering.

Schitsyn, Y., \& Tytkin, Y. (1995). The investigation of the cathode cleaning for the preparation of parts for soldering. Welding in mechanical engineering. M.: TSRDZ.

Sidorov, A. (1987). Restoration of machine parts by spraying and surfacing. M: Mechanical Engineering.

Smirnov, V., Rogovoy, M., \& Povstyan, V. (2001). Works of the Russian Institute of Welding in plasma equipment and technologies. Welding in Siberia, 1, 25 -28.

Sosnin, N., Hristofis, B., \& Ermakov, S. (2002). The selection and optimization of the plasma surface hardening processes. Proceedings of the 4th International Practical Conference on technology of repair, restoration, strengthening and renovation of machines, equipment and metal structures, Saint-Petersburg.

Suvorov, N. (1969). Experimental studies of the parameters distribution in the single-phase and two-phase subsonic plasma jets. High Temperature Physics, 7(2), 304-312.

Tsvetkov, Y., \& Panfilov S. (1980). Low-temperature plasma in recovery processes. M.: Nauka.

Vainerman, A., Shorshorov, M., Veselkov, V., \& Novosadov, V. (1969). Plasma-welding deposition of metals. L .: Mechanical Engineering.

\section{Copyrights}

Copyright for this article is retained by the author(s), with first publication rights granted to the journal.

This is an open-access article distributed under the terms and conditions of the Creative Commons Attribution license (http://creativecommons.org/licenses/by/3.0/). 